Markus Berger, Stephanie Eisner, Ruud van der Ent, Martina Flörke, Andreas Link, Joseph Poligkeit, Vanessa Bach, Matthias Finkbeiner

\title{
Enhancing the Water Accounting and Vulnerability Evaluation Model: WAVE+
}

Journal article | Accepted manuscript (Postprint)

This version is available at https://doi.org/10.14279/depositonce-9249

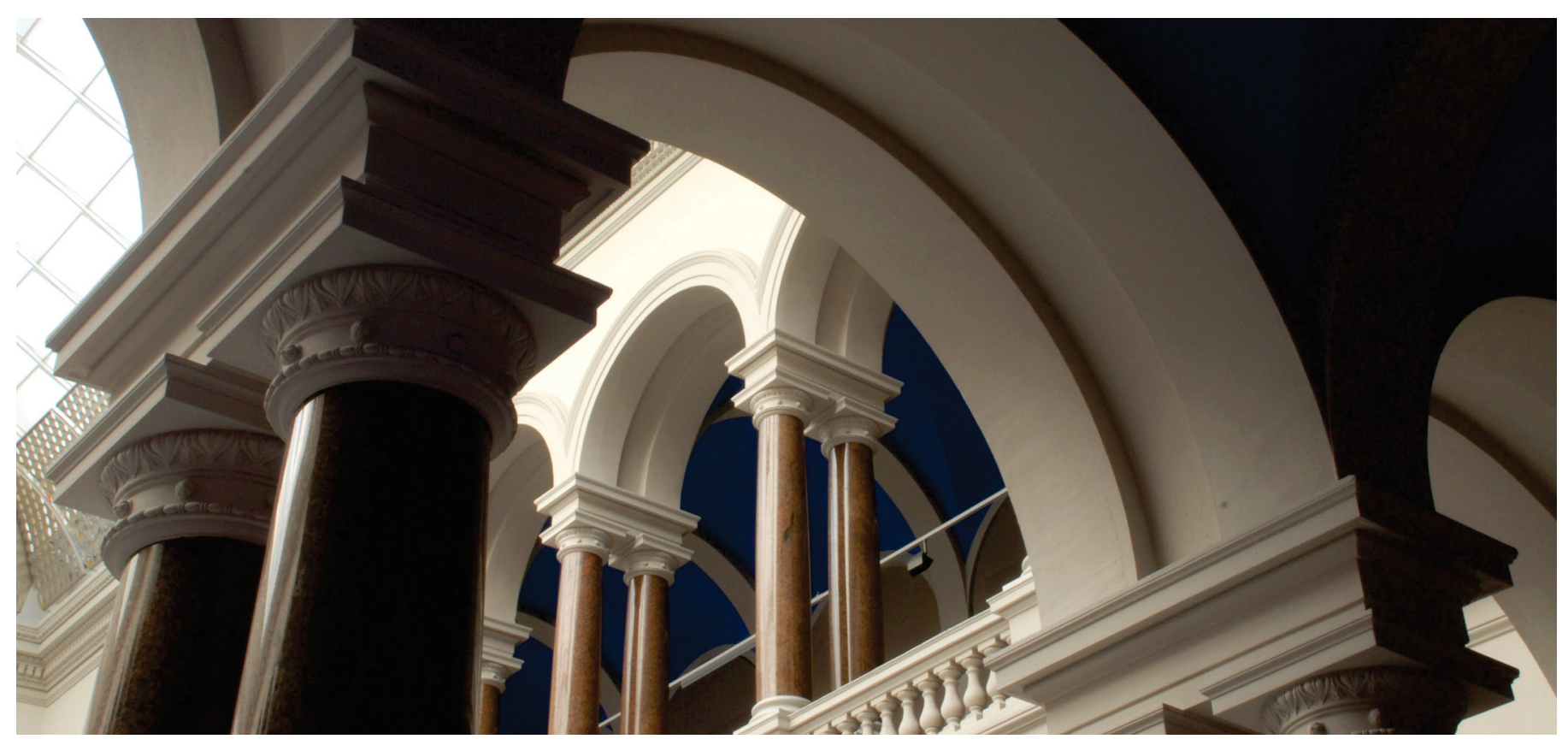

Berger, M., Eisner, S., van der Ent, R., Flörke, M., Link, A., Poligkeit, J., Bach, V., Finkbeiner, M. (2018). Enhancing the Water Accounting and Vulnerability Evaluation Model: WAVE+. Environmental Science \& Technology, 52(18), 10757-10766. https://doi.org/10.1021/acs.est.7b05164 


\section{Enhancing the water accounting and vulnerability}

\section{evaluation model: WAVE+}

Markus Berger ${ }^{1 *}$, Stephanie Eisner ${ }^{2}$, Ruud van der Ent ${ }^{3}$, Martina Flörke ${ }^{4}$, Andreas Link ${ }^{1}$, Joseph

Poligkeit $^{l}$, Vanessa Bach ${ }^{1}$, Matthias Finkbeiner ${ }^{l}$

${ }^{1}$ Technische Universität Berlin, Chair of Sustainable Engineering, Straße des 17. Juni 135, 10623

Berlin, Germany

${ }^{2}$ Norwegian Institute of Bioeconomy Research, P.O. Box 115, NO-1431 Ås, Norway

${ }^{3}$ Utrecht University, Department of Physical Geography, Faculty of Geosciences, P.O. 80.115, 3508 TC Utrecht, The Netherlands

${ }^{4}$ University of Kassel, Center for Environmental Systems Research, Wilhelmshöher Allee 47, 34109 Kassel, Germany

*Corresponding author: e-mail: markus.berger@tu-berlin.de; phone: +49.(0)30.314-25084 
Abstract: Due to the increasing relevance of analyzing water consumption along product life cycles, the water accounting and vulnerability evaluation model (WAVE) has been updated and methodologically enhanced. Recent data from the atmospheric moisture tracking model WAM2layers is used to update the basin internal evaporation recycling (BIER) ratio, which denotes atmospheric moisture recycling within drainage basins. Potential local impacts resulting from water consumption are quantified by means of the water deprivation index (WDI). Based on the hydrological model WaterGAP3, WDI is updated and methodologically refined to express a basin's vulnerability to freshwater deprivation resulting from the relative scarcity and absolute shortage of water. Compared to the predecessor version, BIER and WDI are provided on an increased spatial and temporal (monthly) resolution. Differences compared to annual averages are relevant in semiarid and arid basins characterized by a high seasonal variation of water consumption and availability. In order to support applicability in water footprinting and life cycle assessment, BIER and WDI are combined to an integrated WAVE+ factor, which is provided on different temporal and spatial resolutions. The applicability of the WAVE+ method is proven in a case study on sugarcane and results are compared to those obtained by other impact assessment methods.

Key words: water footprint, water consumption, life cycle assessment, life cycle impact assessment, WAVE+

TOC Art:

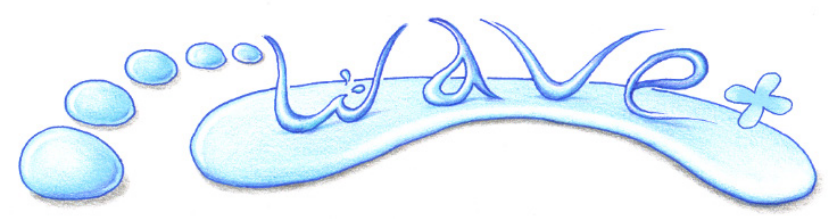




\section{Introduction}

In its recent report 'Global Risks 2018', the World Economic Forum rated the water crisis as one of the main world's challenges - even more severe than food and fiscal crises ${ }^{1}$. The awareness of water scarcity related problems in many parts of the world and their link to daily products and global trade has been raised by concepts like "Virtual Water" ${ }^{2}$ " or initiatives like the Water Footprint Network $^{3}$. More recently, methods assessing local impacts of water use along products' life cycles have been developed resulting in the establishment of an international water footprint standard $(\text { ISO 14046) })^{4}$

Some of those impact assessment methods estimate the local consequences of water consumption based on freshwater scarcity ${ }^{5-9}$. Other methods model the specific cause effect chain of water consumption leading to potential damages on human health (due to malnutrition ${ }^{5,10-11}$ or infectious diseases ${ }^{10,12}$ ), ecosystems (terestrial ${ }^{5,13-14}$, aquatic ${ }^{15}, \operatorname{coastal}^{16}$, wetlands ${ }^{17}$ ), and freshwater resources $^{5,18}$. Comprehensive reviews of existing approaches can be found in refs ${ }^{19-23}$.

One of the scarcity based impact assessment models is the water accounting and vulnerability evaluation model (WAVE) published in Environmental Science and Technology four years ago ${ }^{8}$. On the accounting level, the atmospheric evaporation recycling via precipitation within drainage basins was considered for the first time, which can reduce water consumption volumes by up to $32 \%$. In order to express local impacts of water consumption, WAVE analyzed the vulnerability of basins to freshwater depletion based on local blue water scarcity. The water depletion index (WDI) was determined by relating annual water consumption to availability (runoff) and additionally considering water stocks (lakes and aquifers). In order to consider absolute freshwater shortage in addition to relative scarcity and to avoid that dessert regions show a result of zero if consumption is zero, WDI was set to the highest value in semi-arid and arid basins. 
So far, the WAVE model provided factors for basin internal evaporation recycling and water scarcity on a spatially explicit (basins and countries) but not on a temporally explicit level (monthly data) used in recent methods ${ }^{9,24}$. However, the three parameters water consumption, basin internal evaporation recycling, and water scarcity are expected to show contrary effects during particular seasons. For instance, in dry summer months water consumption can be higher than the annual average, while the basin internal evaporation recycling could be lower and water scarcity can be more severe than the annual means. These contrary effects are expected to lead to an accumulation of inaccuracies when considering an annual temporal resolution. The lack of temporally explicit factors is a severe shortcoming especially for agricultural goods which are produced during particular seasons only.

In order to address the challenge of lacking temporal resolution in WAVE, to update the model based on latest data and methodological findings, and to ease applicability, this work introduces the WAVE+ model. WAVE+ provides a method for the accounting of water use and for assessing potential local impacts of water consumption, which can be used in water footprinting according to ISO $14046^{4}$ and life cycle assessment according to ISO $14044^{25}$. The following sections present the enhancements in the water accounting and the vulnerability evaluation models which can be summarized as follows:

- Data update including increased temporal resolution (monthly) of the basin internal evaporation recycling (BIER) ratio using the atmospheric moisture tracking model WAM2layers $^{26}$

- Data update including increased temporal (monthly) and spatial (5 arcmin instead of 0.5 $\mathrm{deg}$ ) resolution of the water depletion index (WDI) using WaterGAP3 ${ }^{27}$ 
- Methodological refinements in the impact functionand increase in the discriminative power of the WDI factors

- Integrated consideration of a basin's vulnerability to freshwater deprivation resulting from relative scarcity and absolute shortage of water

- Combination of BIER and WDI in an integrated WAVE+ factor promoting applicability

- Provision of WAVE+ factors for sub-basins and world regions in addition to basins and countries

To enable a smooth reading and understanding, the updated results are presented and discussed directly after the description of the methodological enhancements in each section. Subsequently, a case study on the water footprint of sugarcane (to be precise: water scarcity footprint according to ISO 14046) is presented to prove the applicability of the WAVE+ model and to compare results to those obtained by other methods. Furthermore, methodological differences between the WAVE+ model, its predecessor version $(\mathrm{WAVE})^{8}$, and the Available Water Remaining (AWARE) consensus model ${ }^{9}$ of the Water Use in LCA (WULCA) group are discussed along with resulting practical implications.

\section{Water accounting model}

Freshwater consumption denotes the fraction of water use (i.e. total withdrawal), which is not returned to the originating basin due to evapo(transpi)ration, product integration, and discharge into other watersheds or the sea ${ }^{28}$. In practice, water consumption in a basin $n$ and month $k\left(\mathrm{WC}_{n, k}\right)$ is calculated by subtracting waste water discharges $\left(\mathrm{WW}_{n, k}\right)$ from freshwater withdrawals $\left(\mathrm{FW}_{n, k}\right)$. However, this procedure neglects the fact that substantial shares of the evapo(transpi)rative water consumption $\left(E_{n, k}\right)$ and synthetically created vapor resulting from the combustion of fossil fuels 
$\left(V_{n, k}\right)$ can be recycled within the atmosphere via precipitation in relatively short time and length scales $^{29-30}$.

Therefore, the WAVE+ model explicitly accounts for the shares of evapo(transpi)ration $\left(\mathrm{ER}_{n, k}\right)$ and synthetically created vapor $\left(\mathrm{VR}_{n, k}\right)$ which are returned to the originating basin $n$ in the month $k$ via precipitation as shown in Figure 1. Next to waste water discharges $\left(\mathrm{WW}_{n, k}\right)$, those shares are additionally subtracted from freshwater withdrawals $\left(\mathrm{FW}_{n, k}\right)$ to determine the effective water consumption $\left(\mathrm{WC}_{\mathrm{eff}, n, \boldsymbol{k}}\right)$ (Equation 1).

$$
\mathrm{WC}_{\text {eff }, n, k}=\mathrm{FW}_{n, k}-\mathrm{WW}_{n, k}-\mathrm{ER}_{n, k}-\mathrm{VR}_{n, k}
$$

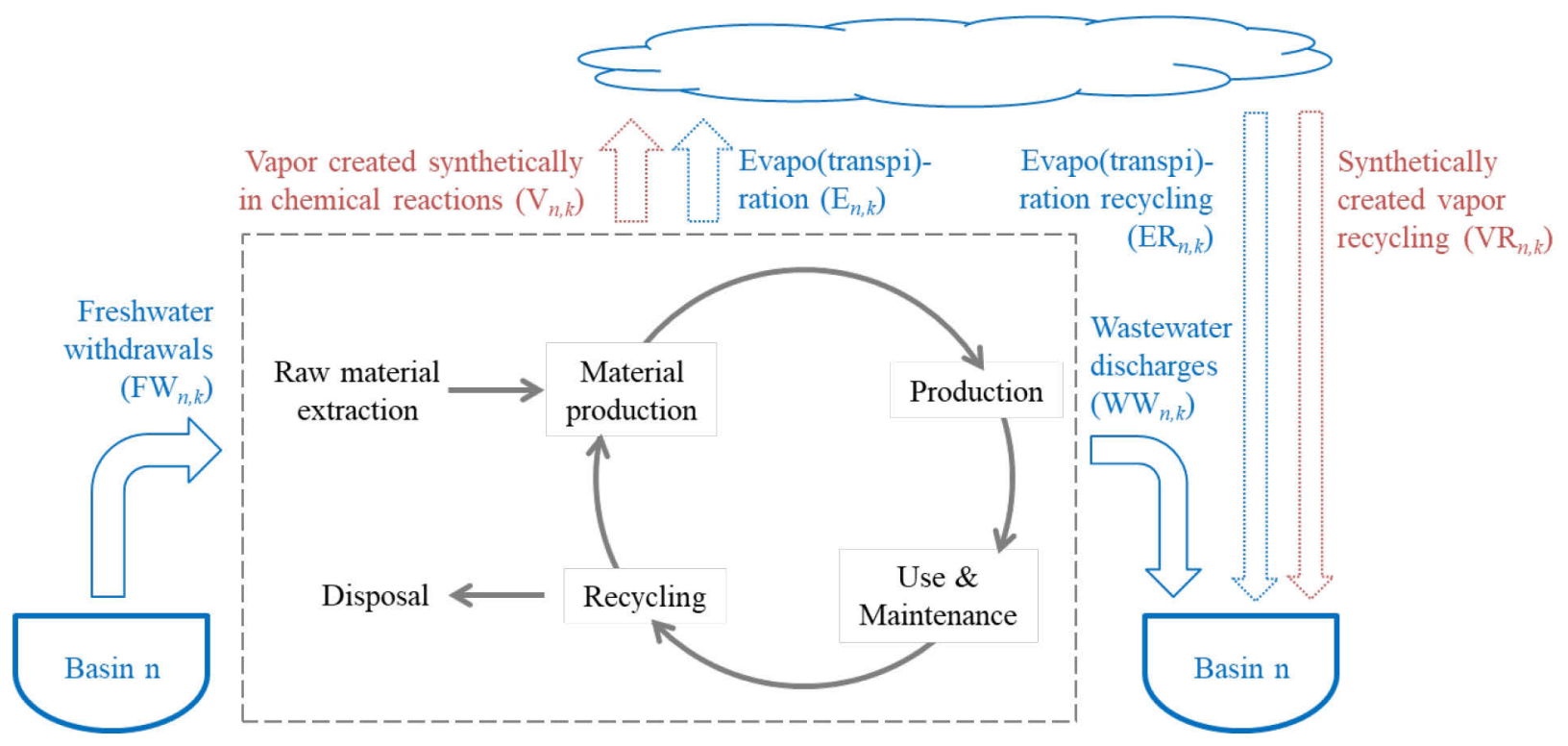

Figure 1. Basin $(n)$ and monthly $(k)$ specific water inventory flows along the life cycle of a product considered in WAVE+

As shown in Equations $2 \mathrm{a}$ and $2 \mathrm{~b}$, the evaporation recycling $\left(\mathrm{ER}_{n, k}\right)$ and vapor recycling $\left(\mathrm{VR}_{n, k}\right)$ within a basin $n$ and month $k$ are determined by multiplying volumes of evapo(transpi)ration $\left(E_{n, k}\right)$ and synthetically created vapor $\left(V_{n, k}\right)$ with the basin internal evaporation recycling ratio $\left(\mathrm{BIER}_{n, k}\right)$ and the runoff fraction $\left(\alpha_{n, k}\right)$. 


$$
\begin{aligned}
& \mathrm{ER}_{n, k}=E_{n, k} \cdot \mathrm{BIER}_{n, k} \cdot \alpha_{n, k} \\
& \mathrm{VR}_{n, k}=V_{n, k} \cdot \mathrm{BIER}_{n, k} \cdot \alpha_{n, k}
\end{aligned}
$$

BIER represent the share of evapo(transpi)ration which is returned to the originating basin via precipitation. It is calculated by means of local evaporation recycling length scales provided by the updated atmospheric moisture tracking model WAM2-layers ${ }^{26}$ in a 1.5 deg resolution. Based on an area-weighted average evaporation recycling length scale for each of the ca. 8.200 basins derived from the hydrological model WaterGAP3 ${ }^{27}$, the BIER values presented in Figure 2 are determined according to the procedure comprehensively described in the original WAVE method ${ }^{8}$. All maps in this manuscript and in the supporting information were created using the ArcGIS software ${ }^{31}$. 


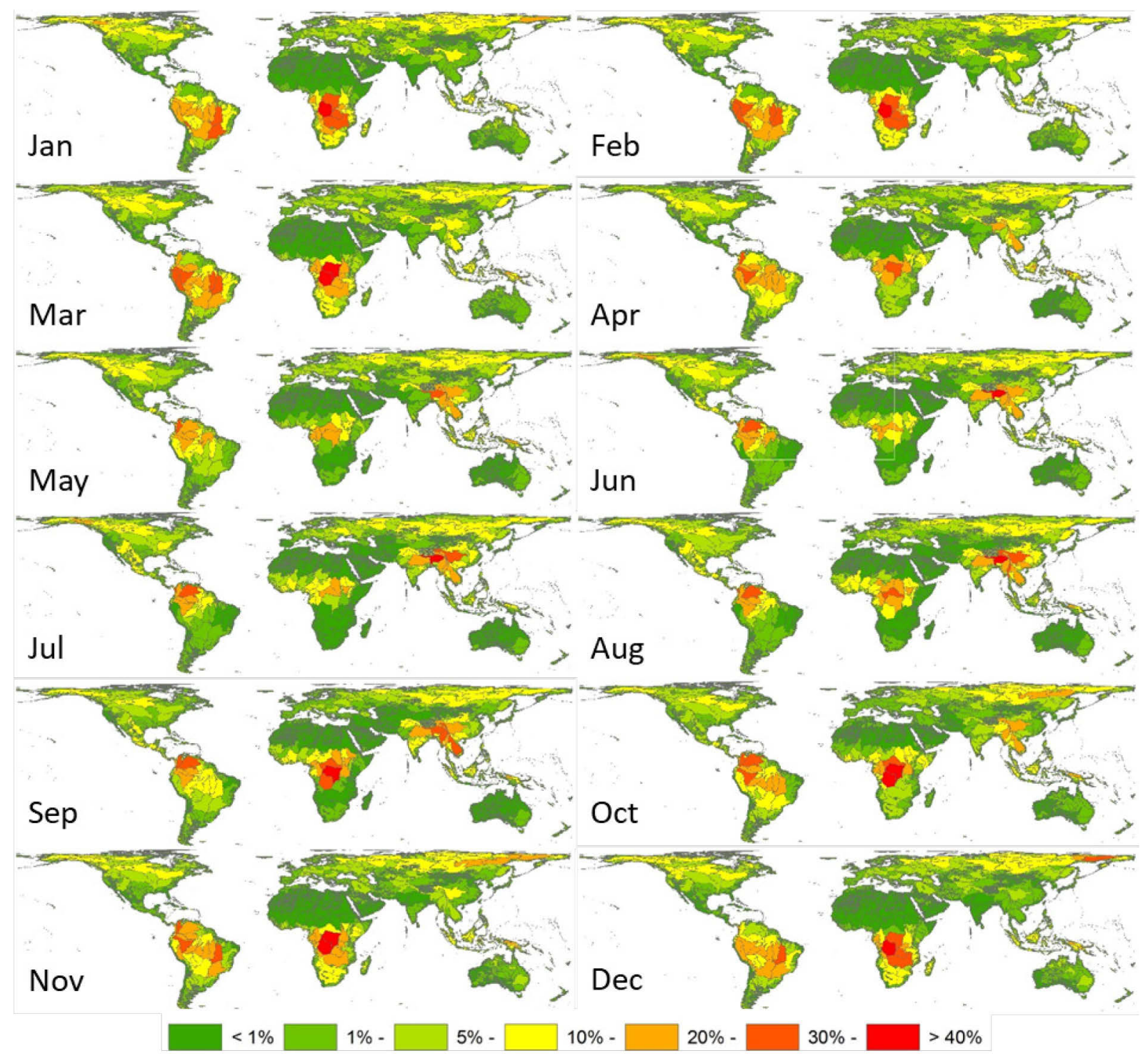

Figure 2. Basin internal evaporation recycling (BIER) ratios denoting the fractions of evaporated water returning to the originating basins via precipitation

As it can be seen in Figure 2, high BIER values above 30\% can be found in South America, the Himalayas and Central Africa. Thus, relevant shares of evapo(transpi)ration and synthetically created vapor can be returned to the originating drainage basin via precipitation. However, these regions show a strong seasonal variation. For example, the BIER values in the Congo basin range from $0 \%$ in July to $50.2 \%$ in December. Since the share of evaporation recycling increases with distance $^{29}$, large drainage basins tend to show higher BIER values than small basins. Figure 2 also 
shows that BIER is very low $(<1 \%)$ in desert areas like the Sahel zone or Central Australia throughout the year. Thus, evaporation recycling can reduce the effective water consumption in water abundant regions whereas the water consumption in water scarce regions remains unaffected.

WAVE+ focuses on blue water (ground- and surface-water ${ }^{2}$ ) and since only a fraction of BIER will be available as runoff (the rest re-evaporates), the runoff fraction $\left(\alpha_{n, k}\right)$ is considered as an additional factor in Equations 2a) and b). It relates the long-term average runoff (R), i.e. groundwater recharge and surface runoff, to the total precipitation $(P)$ within a basin $n$ and month $k$. Updated $\alpha_{n, k}$ factors have been determined based on WaterGAP3 and are shown in Figure S1 in the supporting information. While the runoff fraction is constantly high ( $>60 \%$ in e.g. Ecuador and Peru) or constantly low in some regions $(<20 \%$ in e.g. South Africa or Central Australia), it varies strongly throughout the year in most of the world's basins.

By multiplying BIER $_{n, k}$ (Figure 2) with $\alpha_{n, k}$ (Figure S1), the runoff-relevant basin internal evaporation recycling $\left(\mathrm{BIER}_{\mathrm{runoff}, n, k}\right)$ is determined and shown in Figure $\mathbf{S 2}$ in the supporting information. Since $\alpha$ is particularly low $(<40 \%)$ in Central Africa during those months in which BIER is highest, large BIER ratios determined in e.g. the Congo basin (50.2\% in December) are reduced when considering the runoff fraction of the evaporation recycling ( $17.2 \%$ in December).

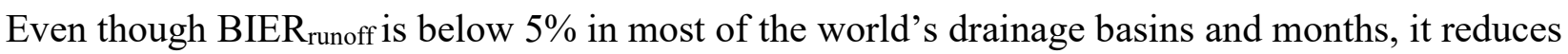
blue water consumption significantly $(10-28 \%)$ in basins in Central Africa, the Himalayas, Ecuador and Peru during parts of the year.

In addition to the basin internal evaporation recycling (BIER), it would also be interesting to consider the basin external evaporation recycling (BEER). As shown in Figure $\mathbf{S 3}$ in the Supporting Information, BEER denotes the fraction of evapo(transpi)ration which returns as precipitation to other than the originating basin. In this way it can be considered that 
evapo(transpi)ration which leaves the originating basin causes water consumption in the originating basin but water gains in the receiving basins. However, predicting the exact locations in which evaporation will return as precipitation is very complex and beyond the scope of this work.

\section{Vulnerability evaluation model}

In addition to determining the effective water consumption on the volumetric level, WAVE+ aims at analyzing the potential local impact that can result from water consumption in a particular basin and month. Similar to other methods ${ }^{5,9}$, these impacts are defined as the risk to deprive other users of using freshwater when consuming water. The risk of freshwater deprivation (RFD) can be determined by multiplying the effective water consumption in each basin $n$ and month $k$ with its corresponding water deprivation index $\left(\mathrm{WDI}_{n, k}\right)$.

$$
\mathrm{RFD}=\sum_{n} \sum_{k}\left(\mathrm{WC}_{\mathrm{eff}, n, k} \cdot \mathrm{WDI}_{n, k}\right)
$$

$\mathrm{WDI}_{n, k}$ denotes the vulnerability of a basin $n$ to freshwater deprivation and, thus, expresses the potential to deprive other users when consuming water in basin $\mathrm{n}$ and month $k$.

Most impact assessment indicators for water consumption ${ }^{5,10,32}$ are based on a ratio of annual water consumption to availability and, thus, express relative freshwater scarcity only. Often this leads to findings that very dry regions, like the Sahel zone or Central Australia, are not water scarce because consumption is close to zero ${ }^{33}$. In WAVE+ we assume that the vulnerability of a basin to freshwater deprivation and thus, the impacts of water consumption, can be influenced by both relative water scarcity and absolute water shortage. We therefore provide water deprivation indexes for relative scarcity $\left(\mathrm{WDI}_{R S}\right)$ and absolute shortage $\left(\mathrm{WDI}_{A S}\right)$ and combine them into an integrated index (WDI) as described in the following subsections. 


\section{Water deprivation index based on relative water scarcity (WDI $\left.I_{R S}\right)$}

The development of $\mathrm{WDI}_{\mathrm{RS}}$ starts with a consumption-to-availability (CTA) ratio, which relates annual water consumption $(C)$ to availability $(A)$. As comprehensively described in the original WAVE method ${ }^{8}$, the CTA is enhanced to a more meaningful water scarcity indicator by additionally considering surface water stocks (SWS) and an adjustment factor for the availability of groundwater stocks ( $\mathrm{AF}_{\mathrm{GWS}}$ ). Recent data for consumption, availability (runoff), and surface water stocks are derived from WaterGAP $3^{27}$. This model provides the data on a 5 arcmin resolution which is aggregated to the basin level. Updated CTA* values, determined for each basin according to Equation 4, are presented in Figure $\mathbf{S 4}$ in monthly resolution.

$$
\mathrm{CTA}_{n, k}^{*}=\frac{C_{n, k}}{A_{n, k}+\mathrm{SWS}_{n, k}} \cdot \mathrm{AF}_{\mathrm{GWS}, n}
$$

The relevance of considering ground- and surface water stocks and the influence of parameter settings in the underlying calculations has been analyzed by a set of sensitivity analyses in the original WAVE paper. It reduces the result of the scarcity assessment by up to $20 \%$ in many water abundant basins and, thus, increases the relative difference between water scarce and water abundant regions. Since the calculation procedure and the underlying data have not changed significantly, the main findings of these analyses are still considered valid.

By means of a logistic function (Figure 3) the physical scarcity ratio CTA* is translated into the vulnerability of a basin to freshwater deprivation expressed by WDIRS, which can be understood as an equivalent volume of water that another user has been deprived of due to a volume of water consumed. 


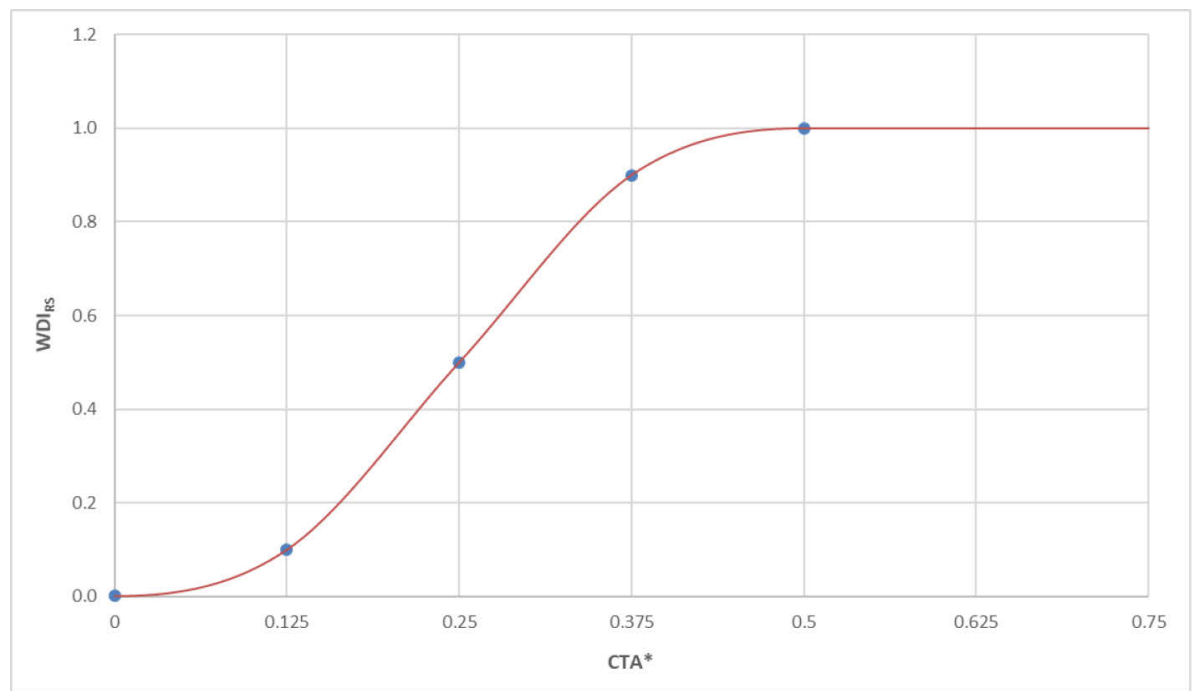

Figure 3. Logistic function determining $\mathrm{WDI}_{\mathrm{RS}}$ based on $\mathrm{CTA}^{*}$; S-curve leads to larger changes in WDI resulting from changes in $\mathrm{CTA}^{*}$ in medium scarcity ranges $0.125<\mathrm{CTA} *<0.375$ compared to low $(\mathrm{CTA}<0.125)$ and high scarcity ranges $(\mathrm{CTA}>0.375)$ and reaches a maximum of 1 at $\mathrm{CTA}^{*}=0.5$

The function shown is fitted to obtain WDI values of $0.001,0.1,0.5,0.9$ and 1 at CTA* values of $0,0.125,0.25,0.375$ and 0.5 , respectively. The resulting S-curve acknowledges the fact that in both water abundant and water scarce regions, the vulnerability of a basin to freshwater deprivation does not rise linearly with the physical scarcity ratio. The WDI values obtained from CTA* according to the logistic function are shown in Figure S5 in the supporting information.

\section{Water deprivation index based on absolute water shortage (WDI $\left.{ }_{A S}\right)$}

In order to acknowledge absolute water shortage, $\mathrm{WDI}_{\mathrm{AS}}$ is determined based on the ratio of potential evapotranspiration (PET) to precipitation $(\mathrm{P})$ derived from WaterGAP3 shown in Figure S6 in the supporting information. According to the function presented in Figure 4, $\mathrm{WDI}_{\mathrm{AS}}$ is set to 0.2 at the semi-aridity threshold $(\mathrm{PET} / \mathrm{P}=2)$ and 0.5 at the aridity limit $(\mathrm{PET} / \mathrm{P}=5)$ as classified by UN Environment ${ }^{34}$. The function is set to reach the maximum of 1 if PET exceeds ten times P. It 
should be noted that this setting represents a model choice to acknowledge that absolute water shortage can influence the vulnerability of a basin to freshwater deprivation and, thus, the potential to deprive other users when consuming water in this basin.

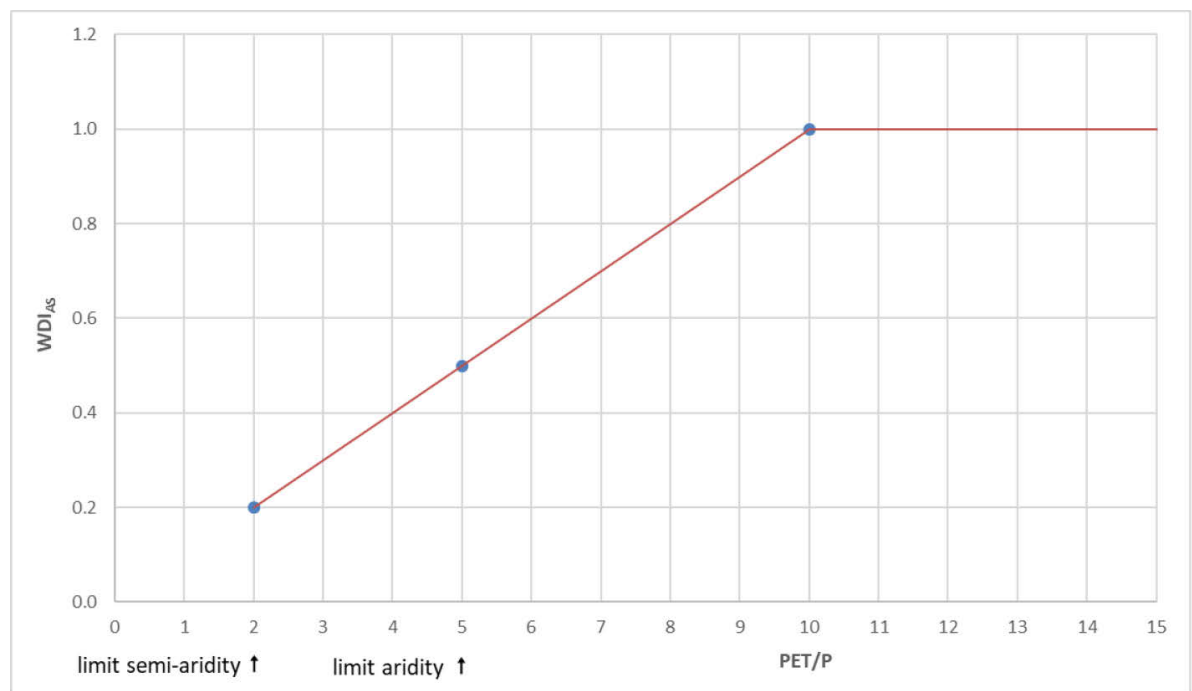

Figure 4. $\mathrm{WDI}_{\mathrm{AS}}$ determined as a function of the ratio of potential evapotranspiration (PET) to precipitation $(\mathrm{P})$

\section{Integrated water deprivation index (WDI)}

After developing water deprivation indexes based on the relative scarcity and absolute shortage of water as described above, an integrated WDI is determined as the maximum of $\mathrm{WDI}_{\mathrm{RS}}$ and $\mathrm{WDI}_{\mathrm{AS}}$ (Figure 5). In most basins and months, $\mathrm{WDI}_{\mathrm{RS}}$ is decisive for the integrated WDI. Absolute water shortage determines the integrated WDI in $28-39 \%$ of the basins. 


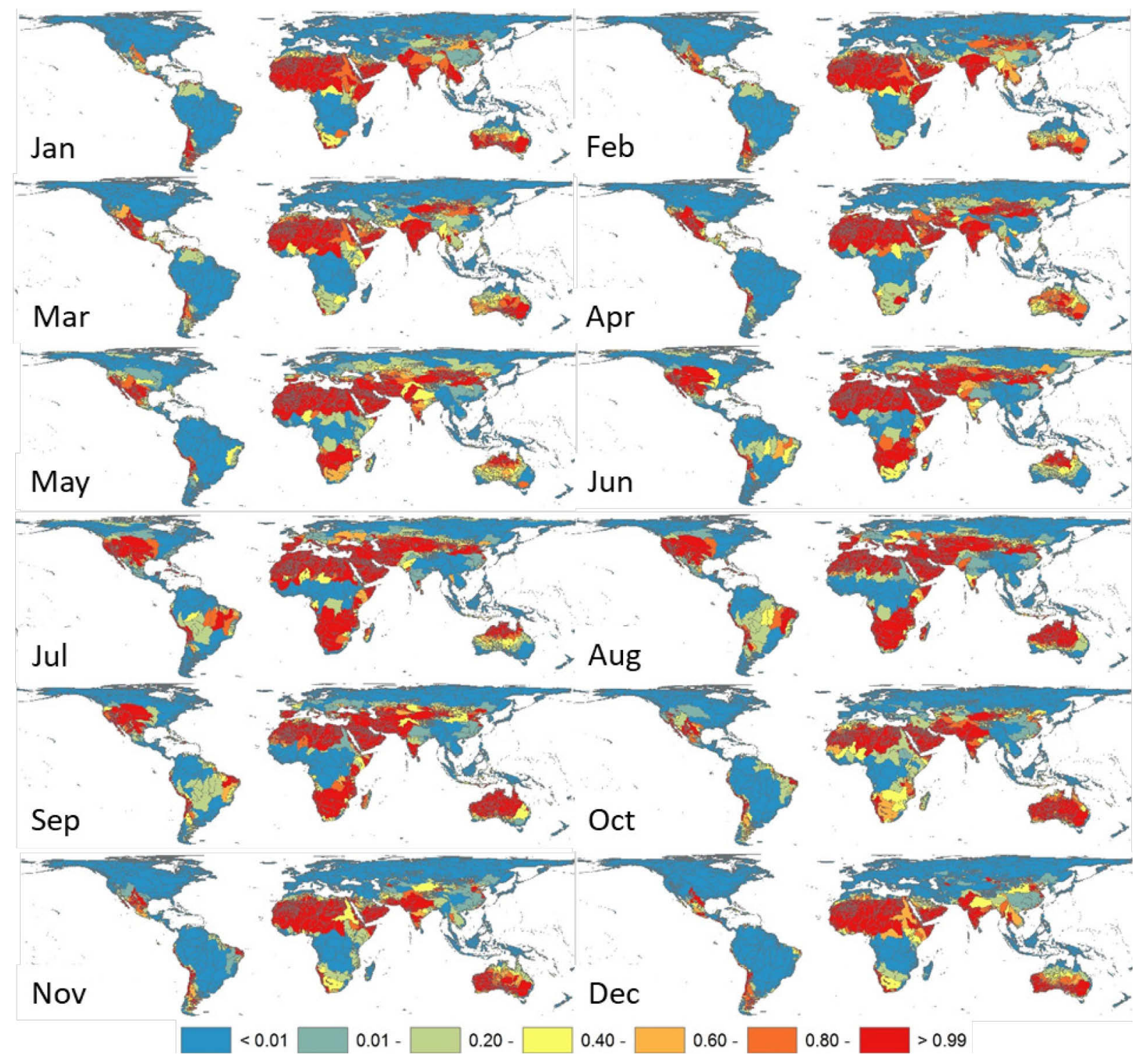

Figure 5. WDI expressing the vulnerability of basins to freshwater deprivation

$\left[\mathrm{m}^{3}\right.$ deprived $/ \mathrm{m}^{3}$ consumed $]$

While WDI is constantly very low throughout the year $(<0.01)$ in large parts of Canada, South America, Central Africa, and Russia, it is constantly very high ( $>0.90)$ in most basins in Northern Africa and the Arabian Peninsula. A strong seasonal variation can be observed in e.g. Argentina, the north-eastern part of Brazil, India, Southern Europe, and the US. 
In most of the world's drainage basins WDI is either very low (blue) or very high (red) with only few basins showing medium (green - orange) water stress. These rather binary results have already been determined for the $\mathrm{CTA}^{*}$ values expressing physical water scarcity (Figure S4 in the supporting information). The effect has increased due to the logistic function, which translates CTA* into WDI (Figure 3) This consideration of absolute water shortage in addition to relative scarcity strongly influences the WDI results of particularly dry basins in Northern and Southern Africa, the middle East, Central Asia, and Australia. The magnitude of this change is shown in Figure $\mathbf{S} 7$ in the supporting information.

As any other impact assessment method for water use, WAVE+ assumes that impacts result from a shortage of water and not from too much water, which can be relevant in basins and months with high precipitation leading to risks of flooding, etc. Here water consumption could be considered having a positive impact and evaporation recycling could be disadvantageously. However, this impact pathway is beyond the scope of this work.

\section{Combining water accounting and vulnerability evaluation: WAVE+ factors}

The consideration of the basin internal evaporation recycling (BIER) and the evaluation of a basin's vulnerability to freshwater deprivation by means of WDI are considered as two separate steps because BIER only applies to the evapo(transpi)rative fraction of consumptive water use. Other forms of water consumption ${ }^{28}$, i.e. integration of water in products or discharge into other basins and sea water, cannot be reduced by means of BIER. Moreover, it is intended to allow for a consideration of the atmospheric recycling of synthetically created vapor, which requires to determine the effective water consumption (Equation 1) before the analysis of local impacts (Equation 3). 
However, in practice most water consumption occurs due to evapo(transpi)ration and the chemical creation of water in the combustion of fossil fuels is rather low. Therefore, an integration of BIER and WDI in the newly introduced WAVE+ factors is proposed, which is provided in addition to the individual BIER and WDI factors. As shown in Equation 5, WAVE $+_{n, k}$ is determined by reducing $\mathrm{WDI}_{n, k}$ by the share of water returned to the originating basin $n$ in month $k$ as blue water $\left(\mathrm{BIER}_{\mathrm{runoff}, n, k}\right)$. WAVE+ factors are presented in Figure $\mathbf{S 8}$ in the supporting information. Since BIER is relatively high in water abundant basins and relatively low in water scarce regions (Figure S2 and S5), the difference between those basins is increased when combining BIER and WDI in the WAVE+ factors.

$$
\mathrm{WAVE}_{n, k}=\left(1-\mathrm{BIER}_{\text {runoff }, n, k}\right) \cdot \mathrm{WDI}_{n, k}
$$

The use of the integrated WAVE+ factors is recommended in cases in which evapo(transpi)ration is the dominant form of water consumption (instead of product integration or discharge into other basins or the sea) and in which no relevant amounts of synthetically created vapor are expected. In such cases the risk of freshwater deprivation (RFD) can be determined by multiplying the basin and month specific water consumption $\mathrm{WC}_{n, k}$ with its corresponding $\mathrm{WAVE}{ }_{n, k}$ factor and by aggregating the results (Equation 6).

$$
\mathrm{RFD}=\sum_{n} \sum_{k}\left(\mathrm{WC}_{n, k} \cdot \mathrm{WAVE}_{n, k}\right)
$$

\section{Spatial and temporal aggregation}

The BIER, WDI and WAVE+ factors are determined on the level of drainage basins in a monthly resolution. Even though this reflects hydrologic conditions best, inventory information on where and when water consumption occurs along supply chains is often not available on such a detailed geographic and temporal resolution. Therefore, the BIER, WDI and WAVE + factors are 
additionally provided in an aggregated form on the annual level and on the levels of countries and world regions. The aggregation methodology and results are presented in the supporting information.

Since the hydrological situation in humid and hyper-arid basins is rather constant throughout the year, monthly WAVE+ factors presented in Figure S8 do hardly vary over the year and, thus, don't show significant differences to the annual average WAVE+ factors (Figure S9). Hence, a temporally explicit assessment of water consumption in many basins in Russia or Northern Africa is favorable but not urgently necessary. In contrast, a monthly assessment is highly relevant in semi-arid and arid basins located in e.g. Chile, Spain or the US as severe changes throughout the year have been identified in both atmospheric moisture recycling and water scarcity. Especially in those regions a temporally explicit assessment of water consumption is strongly recommended for agricultural product systems, which consume water during a particular season only.

\section{Case study}

In order to test the applicability of the WAVE+ model, to analyze the validity of results and to compare the results to those obtained by other methods, a case study on the water footprint of sugar cane production in Australia, Thailand and Columbia is conducted. Since only water consumption but no pollution is considered, this study represents a water scarcity footprint according to ISO $14046 .^{4}$

Based on the monthly and basin-specific blue water consumption of growing $1 \mathrm{t}$ of sugarcane provided by Pfister and Bayer ${ }^{24}$ and based on the production shares of the basins in a country, the country-annual average blue water consumption of sugarcane has been determined. Depending on the resolution of the impact assessment method, either the annual country average or the underlying 
monthly and basin-specific water consumption data can be used for analyzing the resulting local consequences.

Subsequently, the water consumption is multiplied by the impact factors of the WAVE+ method, the predecessor WAVE model ${ }^{8}$ as well as the AWARE $9, \mathrm{WSI}^{5,24}$, and Eco-scarcity ${ }^{6}$ methods. Results of the predecessor WAVE model $^{8}$ have been determined by first reducing the water consumption by the share of the basin internal evaporation recycling returning as blue water (BIER $R_{\text {runoff }}$ and then multiplying the effective water consumption with WDI. This procedure is combined in the WAVE+ factors (Equation 5). Since WAVE+, AWARE and WSI provide monthly and basin-specific impact factors in addition to an annual country average factor, they are applied in both resolutions. Next to a comparison between countries, this allows for analyzing the difference between an annual country average and a monthly and basin specific assessment. Absolute results are shown in Table S1 in the supporting information.

Figure 6 shows the water consumption and impact assessment results of the WAVE, WAVE+, AWARE, WSI and Eco-Scarcity methods on a relative scale normalized to the highest result of each method. Differences in results obtained by the five methods are comprehensively discussed in the supporting information. 


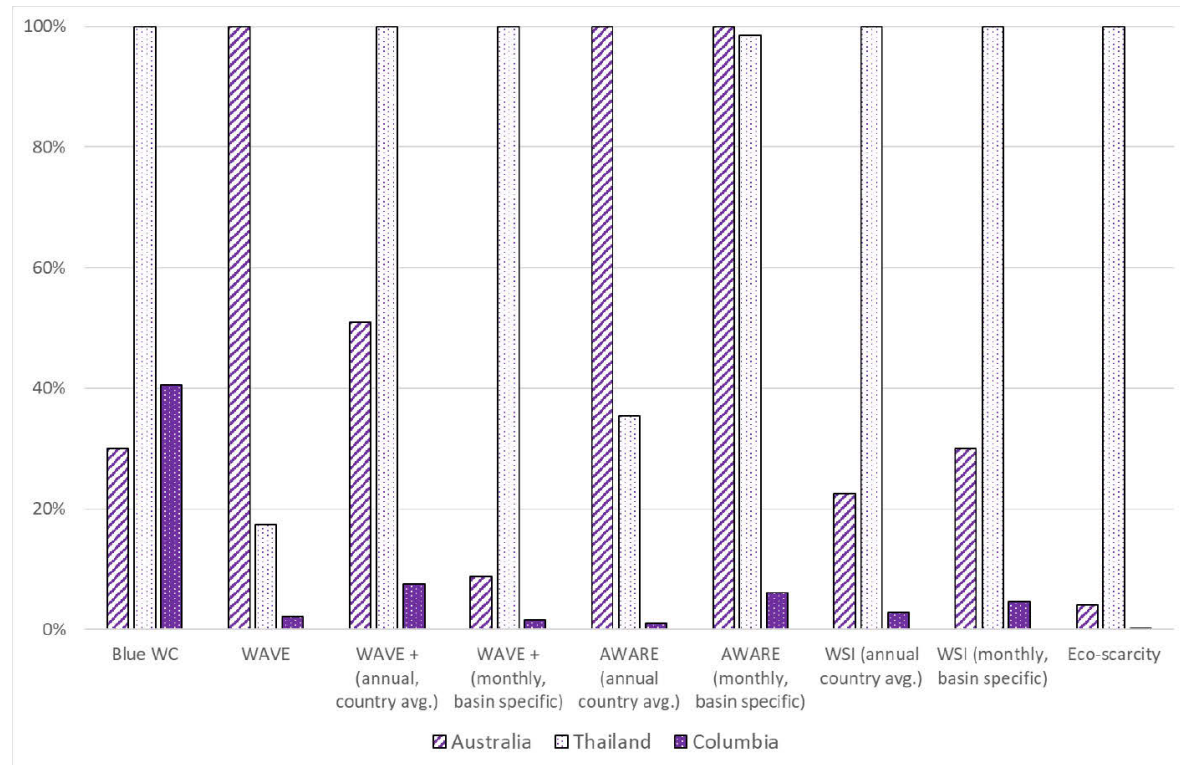

Figure 6. Relative presentation of blue water consumption for producing $1 \mathrm{t}$ of sugar cane in different countries and potential impacts determined by means of the WAVE, WAVE+, AWARE, WSI, and Eco-scarcity methods (based on annual country average and monthly and basin specific impact factors when possible)

\section{Discussion}

A specific discussion of the updated and methodologically enhanced BIER, $\alpha$, BIER $_{\text {runoff, WDI, }}$ and WAVE+ factors as well as the interlinkages between them and the influence of methodological choices has already been presented in combination with the results in the previous sections. A general discussion on the consideration of BIER in water footprinting, the advanced water scarcity assessment by means of WDI, and on further methodological aspects like the additional consideration of water quality degradation has already been presented in the original WAVE publication $^{8}$. Since those findings are valid for WAVE+ as well, this section focuses on discussing specific methodological aspects of the WAVE+ method and on the differences between WAVE+ and the predecessor WAVE model. Additionally, a discussion of methodological differences to the AWARE model $^{9}$ developed by the WULCA group is presented along with a quantitative 
comparison of the impact factors. Additionally, practical implications of methodological differences as well as hints when to use which method are provided.

\section{Comparison $W A V E+$ and $W A V E$}

The WAVE+ model presented in this work updates the data base of the predecessor version ${ }^{8}$ and contains several methodological enhancements. The individual improvements of WAVE+ compared to WAVE are summarized in Table S2 in the supporting information and discussed below.

Recent data from the atmospheric moisture tracking model WAM2-layers ${ }^{26}$ is used to update the basin internal evaporation recycling (BIER) ratio. The main improvement of WAM2-layers is a better representation of moisture tracking in a system with wind shear (e.g. in West Africa), by the addition of a second atmospheric layer instead of merely having one layer. The horizontal moisture transport with two layers (and vertical exchange between them) is more realistic than moisture tracking with vertically integrated moisture fluxes. The main benefit is that moisture is not assumed to instantly mix over the entire atmospheric column after evaporation. In the beginning it remains in the lower atmosphere where winds are less strong. Hence, in most places the regional evaporation recycling ratios in a grid increase. Thus, the length scales of the local evaporation recycling decrease and BIER will increase in several basins (especially in temperate zones).

With regard to the vulnerability evaluation part of WAVE+, it should be noted that the term "deprivation" used in RFD and WDI has replaced the term "depletion" used in the original WAVE method. This has been done because the term water depletion is used in recent methodological developments of the WULCA group modeling a concrete impact pathway to resource depletion ${ }^{35}$. 
However, WDI is considered as a generic impact factor which does not consider a specific causeeffect chain.

A relevant change compared to the predecessor WAVE model is the consideration of a basin's vulnerability to freshwater deprivation based on the relative scarcity and absolute shortage of water by means of $\mathrm{WDI}_{\mathrm{RS}}$ and $\mathrm{WDI}_{\mathrm{AS}}$, which are later combined to an integrated assessment (WDI).

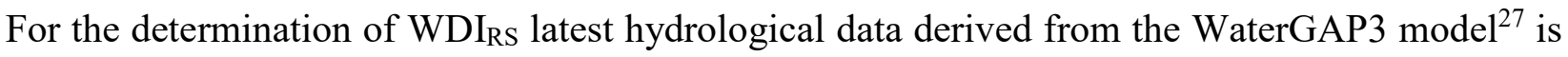
used, which describes a climate period from 1981 to 2010 and increases the spatial resolution from a 0.5 deg grid used in WaterGAP2 $2^{36-37}$ to a 5 arcmin resolution. Since the hydrological data is aggregated from grid-scale to basins, the increased spatial resolution allows for a more precise basin delineation and leads to a finer detailing of small coastal basins. This has increased the number of basins from ca. 11,700 considered in WAVE to ca. 135,000 basins in WAVE+. However, uncertainty can be high in very small basins (mainly consisting of one 5 arc minute grid cell only) due to uncertainties in the coarse meteorological data driving WaterGAP3 and in the physiographic input data. For this reasons basins $<1,000 \mathrm{~km}^{2}$ have been merged with their nearest valid neighbor basin $\left(>1,000 \mathrm{~km}^{2}\right)$ within a distance of max. $100 \mathrm{~km}$ (Figure S11). If no basin $>$ $1,000 \mathrm{~km}^{2}$ was available within $100 \mathrm{~km}$, small neighboring basins have been combined to basin groups. In this way, WAVE+ distinguishes ca. 8,200 basins. Even though the absolute number of basins decreased compared to WAVE, the basin delineation is more precise and the results are more robust - especially for small coastal basins.

The monthly resolution of underlying hydrological data derived from WaterGAP3 allows for refinements in the setting of the function translating physical scarcity $\left(\mathrm{CTA}^{*}\right)$ into potential impacts (WDIRS) : The logistic function shown in Figure 3 turns 1 at a CTA* of 0.5 (considered as the threshold for severe water stress) instead of 0.25 in the predecessor WAVE model. Setting 
$\mathrm{WDI}_{\mathrm{RS}}$ to 1 at a medium level of physical water stress was necessary because an annual average CTA* $^{*}$ of 0.25 implies that significantly higher water stress can occur during particular months ${ }^{38}-$ especially in semi-arid regions. Fitting the S-curve to turn 1 at a CTA* of 0.5 in the new monthly assessment is considered to reflect water stress more realistically and also led to a stronger spreading of the WDIRS factors.

A main challenge in the determination of monthly $\mathrm{WDI}_{\mathrm{RS}}$ factors is the consideration of intra annual storage capacities within basins ${ }^{24}$. This has partly been addressed due to the consideration of reservoirs as well as ground- and surface water stocks in WDIRs. Moreover, a monthly temporal resolution requires a higher spatial resolution in basins where the flow time from spring to mouth is longer than one month ${ }^{24}$. Since a basin delineation has been used in which the 35 largest drainage basins have been divided into sub-basins, the flow time is shorter than one month in each (sub)basin.

Case studies ${ }^{39-40}$ conducted with the predecessor WAVE model have revealed a shortcoming regarding the limited discriminative power of the $\mathrm{WDI}_{\mathrm{RS}}$ factors. Ranging from 0.01 to 1 , impact assessment results have been mainly influenced by the volume of water consumed. For example, a water consumption of 1 liter in a highly water stressed region could not be identified as a hotspot as long as a water consumption of more than 100 liters occurred in a water abundant region. For this reason the spreading of WDIRS has been increased by one order of magnitude now ranging from 0.001 to 1 . As also discussed in the AWARE consensus model ${ }^{9}$, a spreading of the impact factor by three orders of magnitude represents the best compromise to balance the influence of the inventory and impact assessment phases on the water scarcity footprint result.

Concerning absolute water shortage, WAVE+ contains a separate indicator $\left(\mathrm{WDI}_{\mathrm{AS}}\right)$ which is determined based on a ratio of potential evapotranspiration to precipitation (Figure 4). Compared 
to setting WDI to the maximum in semi-arid and arid basin in a binary way in the predecessor model, the new procedure enables a gradual analysis of potential impacts resulting from aridity. By combining $\mathrm{WDI}_{\mathrm{AS}}$ and $\mathrm{WDI}_{\mathrm{RS}}$ to an integrated WDI, WAVE+ acknowledges that a basin's vulnerability to freshwater deprivation can be determined by the relative scarcity or absolute shortage of freshwater.

When comparing BIER and WDI determined based on annual data of the predecessor WAVE model to the annual BIER and WDI values of the WAVE+ model, which have been determined based on consumption weighted averages of the underlying monthly data, several differences can be observed. The annual average basin internal evaporation recycling tends to be lower in the WAVE + model. This can be explained by the fact that BIER is lower in dry months in which the water consumption is usually higher. Due to the weighting based on monthly consumption shares, the relatively low BIER values of those dry months dominate the annual averages. Comparing the annual average WDI values of the WAVE+ model (Figure S10) to the WDI of the predecessor version, a more diverse spreading of the WDI values can be observed. This is because the rather binary WDI results obtained in WAVE+ on the monthly level have been obtained in a similar form in WAVE on the annual level. However, in WAVE+ the seasonal variation between relatively low water stress in the wet season and comparably high water stress in the dry season is balanced due to the creation of annual averages.

In contrast to the predecessor version, the WAVE+ model provides integrated WAVE+ factors which combine the consideration of BIER on the inventory level and the evaluation of potential local consequences by means of WDI on the impact assessment level (Equation 5). In combination with the provision of annual-, country-, and world region average WAVE+ factors in addition to 
monthly, basin, and sub-basin specific factors, the applicability of the WAVE+ model has been increased significantly.

\section{Comparison WAVE+ and AWARE}

A direct comparison between the WAVE+ and the WULCA group's consensus model AWARE is challenging since the two methods have partly different scopes and follow different modelling approaches. AWARE does not consider effects of atmospheric evaporation recycling considered by means of BIER in WAVE+. The impact assessment model is based on the available water remaining after human and ecosystem water demands have been met (availability minus demand, AMD). Instead of a difference, WAVE+ is based on a ratio of human consumption to availability (considering ground and surface water stocks, CTA*) which is translated into a basins vulnerability to freshwater depletion by means of a logistic function (WDIRS). .In order to acknowledge a basin's absolute water shortage, AMD is related to the basin's area in the AWARE method. The inverse of the basin's area specific availability (low availability leads to high impacts) is divided by the global average area specific availability. This ratio is used as the final impact factor in an interval between 0.1 and $100\left[\mathrm{~m}^{3}\right.$ world eq $\left./ \mathrm{m}^{3}\right]$. In the WAVE + method, absolute water shortage is considered by a separate impact factor $\left(\mathrm{WDI}_{\mathrm{AS}}\right)$ which is determined based on a ratio of potential evapotranspiration to precipitation. The integrated WDI varies by a factor of 1,000 as well $(0.001$ to 1) but is not put in relation to a global average because it expresses an equivalent volume of water another user is deprived of due to a volume of water consumed $\left[\mathrm{m}^{3}\right.$ deprived $/ \mathrm{m}^{3}$ consumed].

A quantitative comparison of the annual and country average impact factors of WAVE + and AWARE is accomplished by means of a regression analysis presented in Figure $\mathbf{S 1 2}$ in the supporting information. The comparison shows that the impact factors of most countries are higher in WAVE+ than in AWARE on a relative level. The main reason for this is the different and more 
stringent way of considering absolute water shortage in WAVE+ described above. As shown in Figure S7, this setting significantly increases the WDI of many basins (and thus countries) throughout the year. The correlation analysis also shows a few extreme outliers (Uganda, Rwanda and Burundi) in which the relative AWARE factors are up to 200 times higher than the relative WAVE+ factors. The reason for this can be found in the different water scarcity results in the Kagera basin, which is the main basin of those three countries. As shown in Figure S13 in the supporting information, this basin is considered as highly water scarce throughout the year in AWARE and as water abundant throughout the year in WAVE+. The reason for this significant difference is the consideration of the environmental water requirement (EWR) in the AWARE method $^{9}$, which is determined as a percentage $(30-60 \%)$ of the pristine (without human intervention) water availability. In case of the Kagera basin this percentage of the pristine availability is even larger than the today's water availability because surface runoff and groundwater recharge have been strongly influenced by the extensive agricultural practice in this region around Lake Victoria. For this reason, the available water remaining is negative and a maximum impact factor is obtained in AWARE. A more comprehensive analysis of impact assessment methods, including e.g. a correlation analysis of the WSI, Eco-scarcity, and other methods along with an analysis of modelling choices has been accomplished by Boulay and colleagues $^{41}$.

Considering the methodological and numerical differences between WAVE+ and AWARE, it is challenging to provide a clear recommendation on when to use which method. To a large extend this depends on the goal and scope of the analysis and on the methodological preferences of the user. If, for instance, the practitioner wants to include potential impacts on ecosystems, the AWARE model should be preferred since the environmental water requirement of aquatic species 
is considered in the available water remaining. If, however, the user wants to consider ground- and surface water stocks in the scarcity assessment, the WAVE+ method should be used.

In general, WAVE+ tends to evaluate more countries as relatively water scarce compared to AWARE (Figure S12) which can be considered a disadvantage if only few hotspots are to be identified. However, this more conservative approach can also be advantageous if potential risks shall not be underrepresented.

The consideration of atmospheric evaporation recycling by means of BIER in the WAVE+ method is independent from the impact assessment step. Hence, BIER can be combined with other impact assessment models, like AWARE, to assess the impacts of the effective water consumption (Equation 1) only. This illustrates that the models are not competitive, provide individual strengths and weaknesses and, thus, are recommended to be applied in parallel to analyze the water footprint profile ${ }^{4}$ of the product systems under study.

In order to promote the applicability of the WAVE + model, the BIER, BIER runoff, WDI and WAVE+ factors are made available free of charge in drainage basin, country and world region resolutions on both monthly and annual levels in a Google Earth layer and a spreadsheet: http://www.see.tu-berlin.de/wave/parameter/en/

\section{Supporting information}

Additional explanations, figures, and tables are available in the Supporting Information. These documents are available free of charge via the internet at http://pubs.acs.org. 


\section{References}

1. World Economic Forum Global Risks 2018, 13th Edition; Geneva, Switzerland, 2018.

2. Allan, J. A., Virtual water: a strategic resource, global solutions to regional deficits. Ground Water 1998, 36 (4), 545-546.

3. Hoekstra, A. Y.; Mekonnen, M. M., The water footprint of humanity. Proc. Natl. Acad. Sci. U.S.A. 2012, 109 (9), 3232-3237.

4. ISO 14046, Water footprint - principles, requirements and guidance. International Organization for Standardization, Ed. Geneva, Switzerland, 2014.

5. Pfister, S.; Koehler, A.; Hellweg, S., Assessing the environmental impacts of freshwater consumption in LCA. Environ. Sci. Technol. 2009, 43 (11), 4098-4104.

6. Frischknecht, R.; Steiner, R.; Jungbluth, N., The Ecological Scarcity Method - Eco-Factors 2006 - A method for impact assessment in LCA. Federal Office for the Environment: Bern, Swizerland, 2009.

7. Mila i Canals, L.; Chenoweth, J.; Chapagain, A.; Orr, S.; Anton, A.; Clift, R., Assessing freshwater use in LCA: Part I - inventory modelling and characterisation factors for the main impact pathways. Int. J. Life Cycle Assess. 2009, 14 (1), 28-42.

8. Berger, M.; van der Ent, R.; Eisner, S.; Bach, V.; Finkbeiner, M., Water accounting and vulnerability evaluation (WAVE) - considering atmospheric evaporation recycling and the risk of freshwater depletion in water footprinting. Environ. Sci. Technol. 2014, 48 (8), $4521-4528$. 
9. Boulay, A.-M.; Bare, J.; Benini, L.; Berger, M.; Lathuillière, M. J.; Manzardo, A.; Margni, M.; Motoshita, M.; Núñez, M.; Pastor, A. V.; Ridoutt, B.; Oki, T.; Worbe, S.; Pfister, S., The WULCA consensus characterization model for water scarcity footprints: assessing impacts of water consumption based on available water remaining (AWARE). Int. J. Life Cycle Assess. 2018, 23 (2), 368-378.

10. Boulay, A.-M.; Bulle, C.; Bayart, J.-B.; Deschenes, L.; Margni, M., Regional Characterization of Freshwater Use in LCA: Modelling Direct Impacts on Human Health. Environ. Sci. Technol. 2011, 45 (20), 8948-8957.

11. Motoshita, M.; Ono, Y.; Pfister, S.; Boulay, A.-M.; Berger, M.; Nansai, K.; Tahara, K.; Itsubo, N.; Inaba, A., Consistent characterisation factors at midpoint and endpoint relevant to agricultural water scarcity arising from freshwater consumption. Int. J. Life Cycle Assess. 2014, DOI 10.1007/s11367-014-0811-5.

12. Motoshita, M.; Itsubo, N.; Inaba, A., Development of impact factors on damage to health by infectious diseases caused by domestic water scarcity. Int. J. Life Cycle Assess. 2011, $16(1), 65-73$.

13. van Zelm, R.; Schipper, A. M.; Rombouts, M.; Snepvangers, J.; Huijbregts, M. A. J., Implementing Groundwater Extraction in Life Cycle Impact Assessment: Characterization Factors Based on Plant Species Richness for the Netherlands. Environ. Sci. Technol. 2011, (45), 629-635.

14. Lathuillière, M. J.; Bulle, C.; Johnson, M. S., Land Use in LCA: Including Regionally Altered Precipitation to Quantify Ecosystem Damage. Environ. Sci. Technol. 2016, 50 (21), $11769-11778$. 
15. Hanafiah, M. M.; Xenopoulos, M. A.; Pfister, S.; Leuven, R. S. E. W.; Huijbregts, M. A. J., Characterization Factors for Water Consumption and Greenhouse Gas Emissions Based on Freshwater Fish Species Extinction. Environ. Sci. Technol. 2011, 45 (12), 5272-5278.

16. Amores, M. J.; Verones, F.; Raptis, C.; Juraske, R.; Pfister, S.; Stoessel, F.; Antón, A.; Castells, F.; Hellweg, S., Biodiversity Impacts from Salinity Increase in a Coastal Wetland. Environ. Sci. Technol. 2013, 47 (12), 6384-6392.

17. Verones, F.; Saner, D.; Pfister, S.; Baisero, D.; Rondinini, C.; Hellweg, S., Effects of consumptive water use on wetlands of international importance. Environ. Sci. Technol. 2013, 47 (21), 12248-12257.

18. Dewulf, J.; Bosch, M. E.; De Meester, B.; van der Vorst, G.; van Langenhove, H.; Hellweg, S.; Huijbregts, M. A. J., Cumulative Exergy Extraction from the Natural Environment (CEENE): A Comprehensive Life Cycle Impact Assessment Method for Resource Accounting. Environ. Sci. Technol. 2007, 41, 8477-8483.

19. Berger, M.; Finkbeiner, M., Water footprinting - how to address water use in life cycle assessment? Sustainability 2010, 2 (4), 919-944.

20. Kounina, A.; Margni, M.; Bayart, J.-B.; Boulay, A.-M.; Berger, M.; Bulle, C.; Frischknecht, R.; Koehler, A.; Canals, L. M. i.; Motoshita, M.; Núñez, M.; Peters, G.; Pfister, S.; Ridoutt, B.; Zelm, R. v.; Verones, F.; Humbert, S., Review of methods addressing freshwater use in life cycle inventory and impact assessment. Int. J. Life Cycle Assess. 2013, 18 (3), 707-721.

21. Núñez, M.; Bouchard, C.; Boulay, A. M.; Bulle, C.; Margni, M., Critical analysis of life cycle impact assessment methods addressing consequences of freshwater use on 
ecosystems and recommendations for future method development. , DOI: 10.1007/s11367016-1127-4. Int. J. Life Cycle Assess. 2016, 21 (12), 1799-1815.

22. Berger, M.; Pfister, S.; Motoshita, M., Water Footprinting in Life Cycle Assessment - How to count the drops and assess the impacts? In Encyclopedia of Life Cycle Assessment, Finkbeiner, M., Ed. Springer: Dodrecht, The Netherlands, 2016; Vol. 1.

23. Quinteiro, P.; Ridoutt, B. G.; Arroja, L.; Dias, A. C., Identification of methodological challenges remaining in the assessment of a water scarcity footprint: a review. The Int. J. Life Cycle Assess. 2018, 23 (1), 164-180.

24. Pfister, S.; Bayer, P., Monthly water stress: spatially and temporally explicit consumptive water footprint of global crop production. Journal of Cleaner Production 2014, 73 (1), 52 62.

25. ISO 14044, Environmental management - Life cycle assessment - Requirements and guidelines (ISO 14044:2006). International Organisation for Standardisation, Ed. Geneva, Switzerland, 2006.

26. van der Ent, R. J., A new view on the hydrological cycle over continents, PhD thesis, Delft University of Technology, doi:10.4233/uuid:0ab824ee-6956-4cc3-b530-3245ab4f32be. 2014.

27. Eisner, S. Comprehensive evaluation of the WaterGAP3 model across climatic, physiographic, and anthropogenic gradients; Dissertation University of Kassel; Available online: https://kobra.bibliothek.uni-kassel.de/handle/urn:nbn:de:hebis:34-2016031450014 (accessed 29 September 2017). 2016. 
28. Bayart, J. B.; Bulle, C.; Koehler, A.; Margni, M.; Pfister, S.; Vince, F.; Deschenes, L., A framework for assessing off-stream freshwater use in LCA. Int. J. Life Cycle Assess. 2010, $15(5), 439-453$.

29. van der Ent, R. J.; Savenije, H. H. G., Length and time scales of atmospheric moisture recycling. Atmospheric Chemistry and Physics 2011, 11, 1853-1863.

30. van der Ent, R. J.; Tuinenburg, O. A., The residence time of water in the atmosphere revisited. Hydrol. Earth Syst. Sci. 2017, 21 (779-790).

31. ESRI, https://www.esri.com (accessed 16 July 2018).

32. Bayart, J. B.; Bulle, C.; Margni, M.; Vince, F.; Deschenes, L.; Aoustin, E., Operational characterisation method and factors for a new midpoint impact category: freshwater deprivation for human uses. In Proceedings of the SETAC Europe: 19th Annual Meeting May 31 - June 04, 2009, Gothenborg, Sweden, 2009.

33. Berger, M.; Finkbeiner, M., Methodological challenges in volumetric and impact oriented water footprints. Journal of Industrial Ecology 2013, 17 (1), 79-89.

34. UNEP, World Atlas of Desertification. 2 ed.; Arnold: United Nations Environment Programme, London, 1997; p 192.

35. Pradinaud, C.; Northey, S.; Amor, B.; Bare, J.; Benini, L.; Berger, M.; Boulay, A.-M.; Henderson, A.; Junqua, G.; Lathuillièere, M. J.; Margniz, M.; Motoshitaa, M.; Niblick, B.; Payen, S.; Pfister, S.; Quinteiroy, P.; Sonderegger, T.; Rosenbaum, R. K., Freshwater as a Resource: A consensual framework proposal from WULCA. In Proceedings of SETAC Europe 28th Annual Meeting, May 14-17, Rome, Italy, 2018. 
36. Döll, P.; Kaspar, F.; Lehner, B., A Global Hydrological Model for Deriving Water Availability Indicators: Model Tuning and Validation. Journal of Hydrology 2003, 270 (12), 105-134.

37. Flörke, M.; Kynast, E.; Bärlund, I.; Eisner, S.; Wimmer, F.; Alcamo, J., Domestic and industrial water uses of the past 60 years as a mirror of socio-economic development: A global simulation study. Global Environmental Change 2013, 23 (1), 144-156.

38. Brauman, K. A.; Richter, B. D.; Postel, S.; Malsy, M.; Flörke, M., Water depletion: An improved metric for incorporating seasonal and dry-year water scarcity into water risk assessments. Elem Sci Anth. 2016, 4 (83), 1-12.

39. Berger, M.; Pfister, S.; Bach, V.; Finkbeiner, M., Saving the Planet's Climate or Water Resources? The Trade-Off between Carbon and Water Footprints of European Biofuels. Sustainability 2015, 7 (6), 6665-6683.

40. Berger, M.; Söchtig, M.; Weis, C.; Finkbeiner, M., Amount of water needed to save $1 \mathrm{~m} 3$ of water: life cycle assessment of a flow regulator. Applied Water Science 2017, 7 (3), 1399-1407.

41. Boulay, A.-M.; Motoshita, M.; Pfister, S.; Bulle, C.; Muñoz, I.; Franceschini, H.; Margni, M., Analysis of water use impact assessment methods (part A): evaluation of modeling choices based on a quantitative comparison of scarcity and human health indicators. Int. J. Life Cycle Assess. 2015, 20 (1), 139-160. 